\title{
Molecular Mechanisms of Interactions of Trichoderma with other Fungal Species
}

\author{
Birinchi K. Sarma ${ }^{1, *}$, Sudheer K. Yadav ${ }^{2}$, Jai S. Patel ${ }^{2}$ and Harikesh B. Singh ${ }^{1}$ \\ ${ }^{I}$ Department of Mycology and Plant Pathology, Institute of Agricultural Sciences, Banaras Hindu University, Varanasi \\ 221005, India \\ ${ }^{2}$ Department of Botany, Banaras Hindu University, Varanasi 221005, India
}

\begin{abstract}
Trichoderma species are known globally mostly for the production of industrially useful enzymes as well as their biocontrol ability against plant pathogens. One of the major strategies of biological control is mycoparasitism against fungal pathogens of crop plants. However, till recently the mechanisms of mycoparasitism by biocontrol potential Trichoderma species at molecular level were not clearly understood. The biochemical signaling and the involvement of secondary metabolites that lead to mycoparasitic activities of Trichoderma, in particular, were not very clearly known earlier. Recent findings in this regard revealed that there are a number of signaling cascades activated during the process of mycoparasitism by Trichoderma species against phytopathogenic fungal pathogens. In addition Trichoderma also interacts with beneficial root inhabiting fungi like mycorrhizae. The interaction of Trichoderma species with mycorrhizal fungi is different as during interaction with mycorrhizal fungi different signaling cascades are activated that lead to a synergistic action. In the current review, we gathered updated evidences regarding the signaling cascades that are generated during interactions between Trichoderma species with fungal pathogens resulting mycoparasitism as well as interactions of Trichoderma species with mycorrhizal fungi resulting synergism at molecular level. We also highlighted the role of secondary metabolites that are reported to be associated in the signaling processes.
\end{abstract}

Keywords: cAMP signaling, G-protein, MAP Kinase, mycoparasitism, signal transduction, Trichoderma.

\section{INTRODUCTION}

The fungal species Trichoderma has worldwide occurrence and can be easily isolated from a variety of soils, decomposing woods and other sporocarps. The potentiality of different Trichoderma species as effective biocontrol agents against plant diseases especially those caused by soil borne pathogens have been demonstrated long ago. They directly influence the growth and development of mycelia or other surviving propagules of pathogenic fungi through mycoparasitism commonly by releasing antimicrobial secondary metabolites, secreting enzymes that degrade fungal cell wall and forming structures aimed to restrict pathogen growth [1]. Among the fungal biocontrol agents the significance of Trichoderma is very high due to its mycoparasitic potentiality against a wide range of fungal pathogens such as Botrytis cinerea, Fusarium spp., Pythium spp., Rhizoctonia solani, Sclerotium rolfsii, and Sclerotinia sclerotiorum. Trichoderma strains are being used as an alternative to chemical pesticides to manage various plant pathogens mostly attributed to their mycolytic and antibiosis activities as well as plant host mediated physiological changes $[2,3]$. They produce a number of antimicrobial secondary metabolites such as peptaibols, gliovirin, and gliotoxin known to inhibit a wide range of plant pathogens [4]. Secondary metabolites produced by fungi are normally

*Address correspondence to this author at the Department of Mycology and Plant Pathology, Institute of Agricultural Sciences, Banaras Hindu University, Varanasi 221005, India; Tel: 91-542-6702578;

Fax: 91-542-2368993; E-mail: birinchi_ks@yahoo.com not utilized for achieving growth but they play other important roles while interacting with other organisms through facilitating signal transduction [5, 6]. Mycoparasitism by Trichoderma $[7,8]$ could be explained through the presence of an unusually diverse reservoir of secondary metabolite biosynthetic genes evident from the whole genome sequences of $T$. virens and $T$. atroviride, two proven biocontrol species. Products from most of these genes responsible for production of secondary metabolites are associated with mycoparasitism by Trichoderma species against other microbes. Some of the highly characterized secondary metabolites belong to the groups of pyrones, terpenoids, steroids and polyketides which are non-polar compounds with low molecular mass. Trichoderma spp. also produces nonribosomal peptides, as most other ascomycetes do, such as epipolythiodioxopiperazines (ETPs) and siderophores and many of them are antimicrobial in nature. The precise roles of these compounds in biocontrol by Trichoderma species while interacting with other plant pathogens are yet to be clearly understood. However, many of them are reported to act in concert in a synergistic manner with the cell wall degrading enzymes for enhancing host cell wall lysis [9]. Recently, Malmierca et al. [10] showed that Trichoderma species produce Fusarium orthologues trichothecenes such as trichodermin and harzianum A (HA). Disruption of tri4 gene that hampers biosynthesis of trichothecenes results in lowering down their biocontrol activity against the pathogens Rhizoctonia solani and Botrytis cinerea. The strain due to silenced tri4 gene also reduced expression of some defense genes of the salicylic 


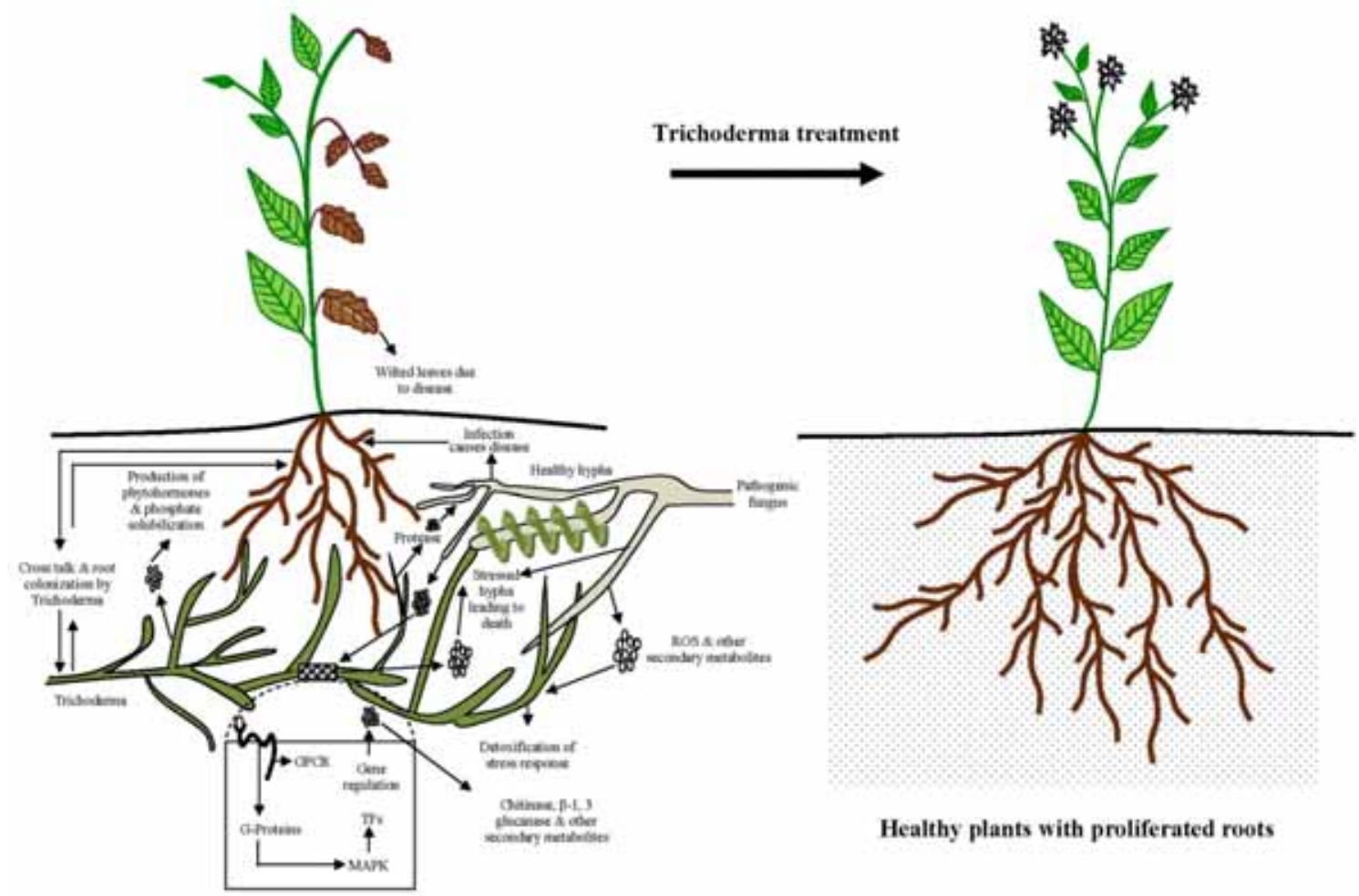

Fig. (1). Molecular mechanisms of Trichoderma interacting with other fungal pathogens.

acid (SA) and jasmonate (JA) pathways in tomato against $B$. cinerea compared to the wild-type strain. Such results indicate that Trichoderma produced HA sensitize the tomato plants pre-treated with Trichoderma and increases the expression of defense genes belonging to SA and JA pathways when challenge against $B$. cinerea. The role of secondary metabolites in fungus-fungus interactions between Trichoderma and other fungal species has recently been reviewed by Mukherjee et al. [11] and therefore not included in this review. Numerous strains of Trichoderma have been shown to interact with other fungi and plants resulting positive impact on the hosts. Trichoderma species not only suppress the growth and development of fungal pathogens but also promote growth of the treated plants and stimulate expression of defence genes. Antagonism, parasitism or even killing other fungi are special and widespread mechanisms prevailed in most of the Trichoderma spp. Biocontrol efficient strains of Trichoderma spp. also establish successfully in the rhizosphere of treated plants where they promote growth of plants and stimulate defence responses when challenged by pathogens $[12,13]$.

\section{HOST RECOGNITION MECHANISMS TRICHODERMA FOR MYCOPARASITISM}

Trichoderma spp. can use dead fungal biomass as a food and therefore, their nutritional strategies comprise of both saprotrophic and biotrophic nature and it will be appropriate to coin them as mycotrophic rather than mycoparasitic. It is observed that highly conserved signaling components are involved when two fungi interact [14]. Trichoderma generally penetrates the host fungus by degrading the cell wall and utilizing their cellular contents. It is achieved with the help of some lytic enzymes including chitinases, glucanases, and proteases that are induced in Trichoderma before directly coming in contact with the host and play major roles in biocontrol [15]. During interaction of Trichoderma with $R$. solani, a special diffusible factor is identified that is released from the host which is responsible for induced transcription of ech42 (endochitinase 42encoding) gene in Trichoderma before getting any physical contact [16]. Similarly, during direct contact between Trichoderma and its host, coiling by Trichoderma mycelia around the hyphae of host is induced by the lectins present in the cell wall of hosts [17]. Production of lytic enzymes and formation of infection structure are triggered by chemical components of host fungus which may be either structural or extracellular and is categorized as induced response [16]. Recent advances in genome sequencing and annotation of Trichoderma genomes have made understanding of these phenomena much simpler. Knowledge regarding molecular physiology of mycotrophic life style of Trichoderma had also been gained through genomic and transcriptomic studies (Fig. 1). However, several genes are also expressed in Trichoderma spp. either away or on contact with the pathogenic fungi $[18,19]$. Such genes are mostly oligopeptide transporter and proteases encoding genes. Many of the proteases encoding genes are from the subtilisin-like serine proteases and are found to be expressed significantly in $T$. harzianum strain CECT 2413 when grown under conditions mimicking biological control [19]. The expression of subtilisin-like proteases encoding genes is also abundant at the contact point between $T$. atroviride and its fungal host species $R$. solani and $S$. sclerotiorum. Overexpression of the proteases gene prbl from $T$. atroviride showed its direct involvement in biocontrol activity through enhanced mycoparasitism. The released oligopeptides bind to the receptors present on the surface of Trichoderma which 
sense nitrogen starvation of $T$. atrovirde [18], a host trapping mechanism very similar to nematophagous fungi, triggered by the nematode released oligopeptides [20]. In Trichoderma, the released oligopeptides are sensed by the class IV G protein-coupled receptors (GPCRs) [18]. Two paralogous from the class IV GPCRs are present each in $T$. atroviride, $T$. virens and $T$. jecorina. Some more GPCRs that are associated with sensing the signals from the host were also reported. Gpr1, a GPCR gene from the cyclic AMP pathway, is also found essential in mycoparasitism by T. atroviride [21]. Further, downstream signal transduction from such receptors occur through a conserved $G$ protein signaling cascade which is composed of three subunits, viz., $\mathrm{G} \alpha, \mathrm{G} \beta$ and $\mathrm{G} \gamma$ subunits. Mutants that are defective in the $\mathrm{G} \alpha$ subunit cause loss of function in Tgal and the strain looses mycoparasitic overgrowth on three hosts. The effect is coupled with significant reduction in the activities of chitinase followed by reduced accumulation of the antifungal compound 6-pentyl pyrone [22, 23]. On the other hand the deletion of a tgal homologue $\operatorname{tgaA}$ in $T$. virens also reduced mycoparasitism by the strain on the phytopathogen $S$. rolfsii [24].

\section{SIGNAL TRANSDUCTION IN TRICHODERMA DURING MYCOPARASITISM}

Mycotrophy and mycoparasitism both are signal dependent mechanisms and as mentioned earlier recognition of fungal host released lectins is the most important initial step. However, plant lectins also induce coiling in Trichoderma spp. but lectins released from the plant host do not determine the specificity in attachment of Trichoderma spp. to their hosts [22]. Coiling and mycoparasitism cannot be correlated always as self coiling (coiling around own hyphae) in some Trichoderma spp. is also observed. It needs further investigation to reveal the exact mechanism(s) of induction of coiling. Hyphal growth of Trichoderma spp. takes place along with the host followed by formation of papilla-like structures especially at the point where cell wall degradation and lumen penetration occur prior to mycoparasitism. Trichoderma spp. at this stage behaves like a true fungal pathogen that attacks a plant host. The papillalike structures are very similar to appressorium produced by fungal plant pathogens on the surface of their hosts. Glycerol is produced in these structures that cause increase in turgor and is believed to be essential for exerting mechanical pressure on the host surface that facilitates invasion in to the host cell. At the time of contact during mycoparasitism by T. atroviride, upregulation in lipid catabolism and osmoregulation genes takes place which is very similar to pathogenicity by the fungus Magnaporthe grisea on its plant host rice [18]. Finally, a concerted effort of released antifungal secondary metabolites and lytic enzymes Trichoderma kills the host. Trichoderma genome decoded the presence of a large number of enzymes encoding genes essential for biosynthesis of such antifungal compounds. Among the Trichoderma species, abundance of nonribosomal-peptide synthetases are observed in $T$. virens [24] compared to the other known fungi whereas $T$. atroviride and $T$. virens have many genes that encode several chitinases [25]. Increased chitinase activity is directly correlated with enhanced mycoparasitic ability in
T. harzianum and the cellulose-binding ability facilitates tight binding of chitinases with insoluble substrates of chitin. However, deletion of chitinases genes in different Trichoderma strains did not result in loss of mycoparasitic as well as biocontrol activities suggesting that production of lesser chitinases due to gene redundancy is one of the several mechanisms adopted by Trichoderma spp. for biological control. Trichoderma spp. also contains a large number of chitosanases belonging to the $\mathrm{GH}$ family. $\beta-1,3$-glucan is the second most abundantly present fungal cell wall polymer [26] and $\beta$-1,3-glucanases hydrolyses it. $\beta$-1,6-glucanase homologue Bgn16.3 overexpression in T. harzianum CECT 2413 converted it to a better biocontrol strain with enhanced biocontrol efficacy against $B$. cinerea, $R$. solani and Phytophthora citrophthora. $\beta$-1,6-glucanases overproducing strains of $T$. harzianum and $T$. virens also showed enhanced biocontrol against $B$. cinerea, $R$. solani and $P$. ultimum $[1$, 27]. However, it is still difficult to narrow down one single mechanism that is essentially required for the mycotrophic life style of Trichoderma spp.

\section{MECHANISMS OF SIGNAL TRANSDUCTION IN TRICHODERMA}

Downstream transduction of signals, generated at the site of receptors, is essential for further expression of genes in the host. Three important signal transduction pathways are identified in Trichoderma spp. that enhance the expression of biocontrol and mycoparasitism associated genes. The overexpressed genes belong to the heterotrimeric G-protein signaling, MAPK (mitogen-activated protein kinase) cascades and the cAMP pathways [14]. Most importantly the T. virens MAP-kinase TVK1 and its orthologs TmkA in T. asperellum and TMK1 in T. atroviride [28], are vital in regulating signaling mechanisms for enhanced biocontrol efficiency. Transcript levels of the respective genes also increase in $T$. virens and T. asperellum while interacting with plant roots. Detailed studies of the two genes of the heterotrimeric $\mathrm{G}$ protein signaling pathway viz., the class I (adenylate cyclase inhibiting) G- $\alpha$ subunits TGA1 of T. atroviride and TgaA of $T$. virens as well as the class III (adenylate cyclase activating) G- $\alpha$ subunits TGA3 of $T$. atroviride and GNA3 of $T$. reesei have revealed that functions of these two genes are associated with biocontrol. TGA1 was identified vital in the production of antifungal metabolites and regulating coiling around the host hyphae. Loss of function of TGA1 reduces the growth inhibition effect on the fungal host [22]. Similarly, TgaA was shown to have a host specific involvement associated with the MAPkinases activities whereas TGA3 was found to be important for biocontrol activities as the corresponding gene deletion showed loss of virulence in the strains [29]. Activation of the constitutive GNA3 in $T$. reesei indicates a positive effect on mycoparasitism [30]. The results thus suggest a positive role of MAP-kinases activities and cAMP in biocontrol by Trichoderma species [31].

\section{HETEROTRIMERIC G PROTEIN MEDIATED SIGNALING}

Mycoparasitism is very essential for a successful interaction between a host and a parasite. In such interactions 
host recognition or mycoparasite enzyme-mediated release of host molecules is the initial step. Such signals could be perceived by the release of fungal cell wall degradation products due to the enzymatic action of the mycoparasite either during contact with or while approaching towards the host $[16,32]$. The perception of the molecules by the signal transduction pathways is because of the chemical properties of the signaling compounds. The heterotrimeric $G$ proteins play very crucial roles during antagonism of fungal pathogens in $T$. atroviride and $T$. virens. Significant differences were observed among $T$. atroviride and $T$. virens G-protein signaling despite both being closely-related biocontrol agents. In plant pathogenic as well as in saprophytic fungi the $\alpha$-subunits of G-proteins are involved in different activities such as signal transduction during growth, pathogenicity and production of secondary metabolites. Antagonistic interactions between two fungi provide novel mode of regulation of these conserved signaling elements. When expression of tgal was increased in $T$. atroviride by knocking down the G- $\alpha$ subunit homologue by antisense expression it resulted in reduced extension of hyphae. Interestingly, profuse conidiation was observed in the mutant colonies. Recently, it was confirmed that host-mediated signaling and expression of G- $\alpha$ subunit tgal in $T$. atroviride is very important for the mycoparasitism on the hyphae of $R$. solani. Loss in the signaling function was also found to impair virulence of pathogens in plant-pathogen interactions [33]. The reduced expression of a MAPK (bmpl) and a Gai protein (bcgl) encoding genes have a negative impact on virulence against host plants [34]. The MAPK loss-of function mutants of Trichoderma are less effective in parasitism on $R$. solani sclerotia and totally unable to parasitize the $S$. rolfsii sclerotia. It is now confirmed that the $\operatorname{tg} a A$ mediated pathway is involved in the sclerotial parasitism of $S$. rolfsii but not of $R$. solani. Different functions have been designated to the $T$. atroviride gene $\operatorname{tg} a A$ and its homologue. However, T. virens employs both the MAPK pathway [35] and the G-protein pathway for biocontrol activities in a hostspecific manner. The sclerotia of $S$. rolfsii contain high amount of melanin and thereby makes it difficult to penetrate. Therefore, it requires assistance of some specific enzymes for the biocontrol agents to degrade the outer layer and subsequent penetration. A gene for such degrading enzyme could be the downstream target of the tmkA and $\operatorname{tg} a A$ pathways and thereby these two pathways of $T$. virens are considered to be very important for biocontrol [24].

The signaling via heterotrimeric $G$ protein needs basically three components such as a $G$ protein-coupled receptor (GPCR), a heterotrimeric $\mathrm{G}$ protein $(\alpha, \beta, \gamma$ subunits), and an effector [36]. GCPR proteins have seven common transmembrane domains where the $\mathrm{N}$-terminus reside outside and the $\mathrm{C}$-terminus inside the cytoplasm. When ligands bind to these receptors a conformational change occurs and they release the G- $\alpha$ subunit from the $G$ protein for exchanging GDP with GTP. Subsequently the GTP bound G- $\alpha$ subunit dissociates from their G- $\beta$ and $-\gamma$ subunits and these two signaling units then regulate the downstream activities of the effectors. Receptors are classified into nine groups [37] and class IX comprises of fungal opsins that are quite similar to rhodopsin, the bacterial retinal-binding proteins. Preliminary investigations of the $T$. reese $i$ and $T$. atroviride genomes also revealed that at least 16 putative proteins with 7-transmembrane domains are distributed all over these nine receptor classes. G-proteins were found essential in fungi during sexual multiplication and pathogenic development on a prey. They were also found to be vital in secondary metabolism leading to different developmental as well as morphogenetic processes associated with virulence of mycoparasitic fungi and fungal pathogens of plants. G-protein $\alpha$ subunits are also classified into three major subgroups [38]: subgroup I, subgroup II, and subgroup III. Over-expression of subgroup I $\mathrm{G} \alpha$ subunit Tga1 in T. atroviride showed its involvement in both coiling and conidiation [22] but tgal mutant G-protein $\alpha$ subunit affects processes like vegetative growth, production antifungal metabolites and chitinases [39] that are involved partially in biocontrol by Trichoderma spp. The tgal mutant was also unable to overgrow and lyse host fungi such as $B$. cinerea, $R$. solani, and $S$. sclerotiorum. However, formation of infection structure was not affected and overgrowing ability is reduced possibly due to growth inhibition of the host fungi at an enhanced level because of its overproduction and release of low molecular weight secondary metabolites. Further characterization of mutants of T. atroviride bearing a gpr1-silencing construct of a GPCR revealed that Gpr1 is important for growth, conidial production and germination [40].

\section{MAP KINASE MEDIATED SIGNALING}

Trichoderma spp. are not only restricted to suppression of pathogens but also are opportunistic plant symbionts and triggers systemic resistance in treated plants [41]. Functional MAPK is also essential in signal perception by plants as well as by Trichoderma spp. [42] and the MAPK signaling play important role during Trichoderma-plant interaction and induces plant systemic resistance. However, some contrasting reports are also available regarding the role of MAP Kinases in parasitism by Trichoderma species. When spore germination of Trichoderma took place near the cucumber roots, the tmkA mutants also colonized the cucumber roots as effectively as the wild type strains. The fungal MAPKs play important role in several developmental processes such as hyphal growth, sporulation, mating and pathogenicity [43]. Signal transduction in phytopathogenic fungi takes place via MAPK cascades during parasitic interactions [44]. There are three common MAPKs reported in fungi [45]. MAPK pathways are conserved evolutionarily in all eukaryotic organisms and the three kinases, viz., a MAPK, a MAPK activator and a MEK activator (MEK kinase $=$ MEKK or MAPK kinase kinase) are essentially required for functioning of the MAP kinase pathways. In the MAP Kinase encoding gene mutant strains of Trichoderma, the expression level of mycoparasitism-related genes (MGRs) increases during mycoparasitism when they come in direct conflict with the plant pathogenic fungus $R$. solani. The disease control was more in the null mutants compared to their wild-type strain or a recommended chemical fungicide. It is also found that in $T$. virens the MAP kinase 
Tvk1 serve as negative modulator during the process of host sensing and sporulation. MAPK pathway is involved in transduction of a large variety of signals, amongst which one is associated with pathogenesis. Kss1 from Saccharomyces cerevisiae, a homologue of MAPK have been implicated in the expression of cell degrading enzyme both in phytopathogenic as well as non-phytopathogenic fungi. The transcription of a proteinase-encoding gene ( $p r b l)$ is blocked by limiting nitrogen through addition of a MAP kinase inhibitor in two closely related species $T$. atroviride and T. virens [46]. The best studied MAPKs of Trichoderma are from the yeast family and the fungal extracellular-related kinases (YERK1). The T. virens MAPK homologue was described in two different groups as tmkA and $t v k l$ that have been described encoding the same protein in different $T$. virens strains. Contrasting results about the role of this MAP kinase is that it produced mycoparasitism-related enzymes [47]. Enzyme activities of chitinases and proteases is high in $t v k l$ mutants, but tmkA mutant strains take time compared to $t v k l$ mutants in clearing a chitin containing medium. The protein sequence of $t v k l$ shares a high degree of similarity with other MAPKs such as Pmk1 from M. grisea [48]. Even the three introns reported in $t v k 1$ gene are also reported for other fungal MAPK genes. Tvk1 belong to the family of kinases and extracellular-regulated kinases (ERKs) under the umbrella of the MAPK superfamily. The conserved sequence points out its relation with the YERK1 family reported from both yeast and fungi [49]. MGRs regulation in $T$. virens is very complex, however, they share common elements including Tvk1 like other fungi [50]. The tmkl in $T$. atroviride play a very crucial role in MAPK signaling during its growth and interaction with other fungi. Deletion of $t m k l$ alters the radial growth, conidiation and also spoils the regulation of infection structure formation in the absence of a host-derived signal. In other words, presence of host sensing mechanism will involve a number of signal transduction pathways in Trichoderma spp. that leads to successful expression of MGRs. Molecules either released from the fungal host or located on its surface (e.g. lectins) induce both production of enzyme and formation of infection structure. Production of antimicrobial metabolites such as 6-pentyl-a-pyrone is enhanced in Trichoderma in the presence of a host such as $R$. solani [51]. Characterization of MAPK genes in the rice pathogen $M$. grisea revealed that some of them such as pmk1 and mps1 are essential for pathogenesis including formation of appressoria, colonization on host tissue, and penetration of the host cuticle [52].

\section{CAMP MEDIATED SIGNALING}

cAMP signaling is an important pathway in fungi in controlling of differentiation, sexual development, virulence, monitoring of the nutritional status, stress, transcription and cell cycle progression [53]. The cascade of cAMP signaling is regulated by a membrane-associated adenylate cyclase. Adenylate cyclase synthesizes the intracellular messenger cAMP, which is regulated by $\alpha$-subunits of heterotrimeric Gproteins in most fungi. The cAMP works in eukaryotic organism through the activation of cAMP-dependent protein kinases (PKA) and it consists of two regulatory and two catalytic subunits [54]. cAMP act as a positive effector of endoglucanase induction in $T$. reesei, a species which is able to antagonize and overgrow on $P$. ultimum and provide in planta protection of zucchini plants against $P$. ultimum blight [55]. The exogenous cAMP increased coiling around nylon fibers in the biomimetic system in $T$. harzianum and substances (e.g. dinitrophenol, caffeine, aluminium tetra fluoride) which increased the intracellular levels of cAMP and repressed the synthesis of $\mathrm{N}$-acetyl- $\beta$-D- glucosaminidase [56]. cAMP signaling plays important role during the conidiation in $T$. viride and $T$. atroviride [57]. The mechanism of Trichoderma to survive and disperse in the environment is production of conidia which is induced by environmental factors such as blue light and nutrient stresses in these mycoparasites. In $T$. viride, the photoinduction increases the intracellular level of cAMP due to which conidiation occur [58] and the use of exogenous cAMP stimulate the formation of conidia in both colonies that were kept in the dark and light as well [59]. PKA plays a crucial role in regulation of light responses in this fungus [57]. Deletion of tac1, an adenylate-cyclase-encoding gene, brought intracellular cAMP levels below the detection limit and the mutants showed only 5-6\% of the wild-type growth rate. In mutants, sporulation did not occur in darkness, germination of spores failed in water, did not overgrow the test plant pathogens Pythium sp., R. solani and S. rolfsii and showed reduced secondary metabolite production. It was concluded that cAMP signaling in $T$. virens positively regulates secondary metabolism and Tac1 is the first regulatory protein involved in growth, germination, mycoparasitism and secondary metabolism [60].

\section{INTERACTIONS BETWEEN TRICHODERMA AND MYCORRHIZAL FUNGI}

Arbuscular mycorrhizal fungi (AMF) and biocontrol agent Trichoderma both are helpful in promoting plant growth and improving health when they colonize roots. Fungal biocontrol agents do not cause hindrance on AMF establishment rather facilitates them in a synergistic manner [61]. It is also evident that $T$. harzianum induces the symbiotic association of AMF with vascular plants. A recent study conducted by Al-Asbahi [62] showed that volatile biomolecules released by $T$. harzianum Rifai KRL-AG2 indirectly enhanced association by AM fungi with wheat plant roots (cv. Avocet $\mathrm{S}$ ) and the wheat protein homologous to arbuscular mycorrhizal protein was over-expressed which might have a role to play in the AM-plant interaction. The phytohormone levels particularly auxin and gibberllin were accumulated significantly high in soybean plants when treated with T. harzianum and Glomus mosseae (an AMF) in combination compared to untreated plants and plants treated with $T$. harzianum and $G$. mosseae individually. The observations suggest that there was a synergistic interaction between $T$. harzianum and G. mosseae that resulted in better plant growth [63]. Saprophytic and nonpathogenic strains of Trichoderma reduce the fungal diseases in a variety of plants. Natural inhabitant saprophytic fungi has both positive and negative effect on spore germination, growth, 
development and function of AMF e.g. T. harzianum have different types of effects such as antagonistic, stimulating and neutral effect on AMF [64]. It has been reported earlier that consortia of $T$. harzianum and $G$. intraradices is more effective in lowering the disease severity of Fusarium crown and root rot of tomato and Fusarium wilt of Giotto melon (Cucumis melo L.) caused by Fusarium oxysporum than individually. A number of strains of T. pseudokoningii were found to inhibit germination of AMF e.g. G. mosseae and Gigaspora rosea. Different soluble and volatile substances secreted by $T$. pseudokoningii were attributed to play crucial roles in inhibition of AMF spore germination. While inhibition of spore germination of Gi. rosea is attributed to soluble substances secreted by $T$. pseudokoningii, volatile substances can be attributed to inhibition of spore germination in G. mosseae. Different strains of $T$. pseudokoningii were observed to reduce root colonization percentage by Gi. rosea when treated in soybean culminated in reduced accumulation of shoot dry matter. However, no evidence was generated whether AMF had any adverse effect on propagules of Trichoderma species in most of the instances [64]. This is an interesting area to work further to understand the molecular mechanisms of synergistic and antagonistic interactions between Trichoderma and AMF which is currently very poorly understood [65].

\section{CONCLUSION}

Fungi may interact with each other in a variety of ways. Interactions between two fungal species may be of antagonistic, parasitic and synergistic types. An interaction is normally mediated through cross talk between biomolecules released/secreted from one fungal species that acts as messenger and perceived by receptors present on the other interacting fungal species. A signal is generated at the perception site and further downstream actions follow through a signal transduction mechanism. Downstream transduction of signals further helps in expression of a set of genes that governs the type of interaction that is going to have between the two fungal species. A number of mechanisms had been revealed that are involved in a variety of interactions between the fungal species. More specifically, the interactions between Trichoderma species with other soil fungi has been studied deeper compared to other types of fungal interactions. However, a lot more is needed to be understood about the mechanisms between fungus-fungus interactions particularly mode of interactions between Trichoderma species and AMF as both are essential for promoting plant health and reducing diseases in agricultural crops.

\section{CONFLICT OF INTEREST}

The authors confirm that this article content has no conflict of interest.

\section{ACKNOWLEDGEMENTS}

BKS is grateful to Department of Science and Technology (DST), New Delhi for financial assistance (Grant No. SR/SO/PS-25/10).

\section{REFERENCES}

[1] Djonovic' S, Pozo MJ, Kenerley CM. Tvbgn3, a $\beta$-1,6-Glucanase from the biocontrol fungus Trichoderma virens, is involved in mycoparasitism and control of Pythium ultimum. Appl Environ Microbiol 2006; 72(12): 7661-70.

[2] Howell CR. Mechanisms employed by Trichoderma species in the biological control of plant diseases: the history and evolution of current concepts. Plant Dis 2003; 87(1): 4-10.

[3] Singh A, Jain A, Sarma BK, Upadhyay RS, Singh HB. Rhizosphere microbes facilitate redox homeostasis in Cicer arietinum against biotic stress. Ann Appl Biol 2013; 163: 33-46.

[4] Keswani C, Mishra S, Sarma BK, Singh SP, Singh HB. Unraveling the efficient applications of secondary metabolites of various Trichoderma spp. Appl Microbiol Biotechnol 2014; 98: 533-44.

[5] Hoffmeister D, Keller NP. Natural products of filamentous fungi: enzymes, genes, and their regulation. Nat Prod Rep 2007; 24: 393416.

[6] Osbourn A. Secondary metabolic gene clusters: evolutionary toolkits for chemical innovation. Trends Genet 2010; 26: 449-57.

[7] Druzhinina IS, Seidl-Seiboth V, Herrera-Estrella A, et al. Trichoderma: the genomics of opportunistic success. Nat Rev Microbiol 2011; 9: 749-59.

[8] Kubicek CP, Herrera-Estrella A, Seidl-Seiboth V, et al. Comparative genome sequence analysis underscores mycoparasitism as the ancestral life style of Trichoderma. Genome Biol 2011; 12: R40.

[9] Lorito M, Peterbauer C, Hayes CK, Harman GE. Synergistic interaction between fungal cell wall degrading enzymes and different antifungal compounds enhances inhibition of spore germination. Microbiology 1994; 140: 623-9.

[10] Malmierca MG, Cardoza RE, Alexander NJ, et al. Involvement of Trichoderma trichothecenes in the biocontrol activity and induction of plant defense-related genes. Appl Environ Microbiol 2012; 78: 4856-68.

[11] Mukherjee PK, Horwitz BA, Kenerley CM. Secondary metabolism in Trichoderma - a genomic perspective. Microbiology 2012; 158: 35-45.

[12] Benítez T, Rincón AM, Limón MC, Codón AC. Biocontrol mechanisms of Trichoderma strains. Int Microbiol 2004; 7: 249-60.

[13] Harman GE. Multifunctional fungal plant symbionts: new tools to enhance plant growth and productivity. New Phytol 2011; 189: 647-9.

[14] Zeilinger S, Omann M. Trichoderma biocontrol: signal transduction pathways involved in host sensing and mycoparasitism. Gene Regulation Systems Biol 2007; 1: 227-34.

[15] Hjeljord L, Tronsmo A. In: Harman GE. Kubicek CP, Ed. Trichoderma and Gliocladium. London: Taylor and Francis 1998; 131-52.

[16] Zeilinger S, Galhaup C, Payer K, et al. Chitinase gene expression during mycoparasitic interaction of Trichoderma harzianum with its host. Fungal Genet Biol 1999; 26: 131-40.

[17] Inbar J, Chet I. A newly isolated lectin from the plant pathogenic fungus Sclerotium rolfsii: purification, characterization and role in mycoparasitism. Microbiology 1994; 140(3): 651-7.

[18] Seidl V, Song L, Lindquist E, et al. Transcriptomic response of the mycoparasitic fungus Trichoderma atroviride to the presence of a fungal prey. BMC Genomics 2009; 10: 567.

[19] Suárez MB, Vizcaíno JA, Llobell A, Monte E. Characterization of genes encoding novel peptidases in the biocontrol fungus Trichoderma harzianum CECT 2413 using the TrichoEST functional genomics approach. Curr Genet 2007; 51: 331-42.

[20] Dijksterhuis J, Veenhuis M, Harder W, Nordbring-Hertz B. Nematophagous fungi: physiological aspects and structurefunction relationships. Adv Microb Physiol 1994; 36: 111-43.

[21] Omann M, Zeilinger S. A cAMP receptor-like GPCR is involved in Trichoderma atroviride mycoparasitism. IOBC/WPRS Bull 2009; 43: 105-08.

[22] Rocha-Ramirez V, Omero C, Chet I, Horwitz BA, Herrera-Estrella A. Trichoderma atroviride G-protein alpha-subunit gene tgal is involved in mycoparasitic coiling and conidiation. Eukaryot Cell 2002; 1: 594-605. 
[23] Reithner B, Brunner K, Schuhmacher R, et al. The G protein $\alpha$ subunit Tga1 of Trichoderma atroviride is involved in chitinase formation and differential production of antifungal metabolites. Fungal Genet Biol 2004; 42: 749-60.

[24] Mukherjee PK, Latha J, Hadar R, Horwitz BA. Role of two G-protein alpha subunits, TgaA and TgaB, in the antagonism of plant pathogens by Trichoderma virens. Appl Environ Microbiol 2004; 70: 542-9.

[25] Zexun Lu, Tombolini R, Woo S, Zeilinger S. In vivo study of Trichoderma-pathogen-plant interactions, using constitutive and inducible green fluorescent protein reporter systems. Appl Environ Microbiol 2004; 70: 3073-81.

[26] Latgé JP. The cell wall: a carbohydrate armour for the fungal cell. Mol Microbiol 2007; 66: 279-90.

[27] Ihrmark K, Asmail N, Ubhayasekera W, Melin P, Stenlid J, Karlsson M. Comparative molecular evolution of Trichoderma chitinases in response to mycoparasitic interactions. Evol Bioinform Online 2010; 6: 1-26.

[28] Reithner B, Schuhmacher R, Stoppacher N, Pucher M, Brunner K, Zeilinger S. Signaling via the Trichoderma atroviride mitogenactivated protein kinase Tmk 1 differentially affects mycoparasitism and plant protection. Fungal Genet Biol 2007; 44: 1123-33.

[29] Zeilinger S, Reithner B, Scala V, Peissl I, Lorito M, Mach RL. Signal transduction by Tga3, a novel G protein alpha subunit of Trichoderma atroviride. Appl Environ Microbiol 2005; 71: 1591-7.

[30] Silva R, Steindorff AS, Ulhoa CJ, Felix RC. Involvement of G-alpha protein GNA3 in production of cell wall-degrading enzymes by Trichoderma reesei (Hypocrea jecorina) during mycoparasitism against Pythium ultimum. Biotechnol Lett 2009; 31: $531-6$.

[31] Mukherjee M, Mukherjee PK, Kale SP. cAMP signalling is involved in growth, germination, mycoparasitism and secondary metabolism in Trichoderma virens. Microbiology 2007; 153: 173442.

[32] Corte's C, Gutierrez A, Olmedo V, Inbar J, Chet I, HerreraEstrella A. The expression of genes involved in parasitism by Trichoderma is triggered by a diffusible factor. Mol Gen Genet 1998; 260: 218-25.

[33] Lengeler KB, Davidson RC, D’Souza C, et al. Signal transduction cascades regulating fungal development and virulence. Microbiol Mol Biol Rev 2000; 64: 746-85.

[34] Gronover CS, Kasulke D, Tudzynski P, Tudzynski B. The role of G protein $\alpha$ subunits in the infection process of the gray mold fungus Botrytis cinerea. Mol Plant-Microbe Interact 2001; 14: 1293-302.

[35] Mukherjee PK, Latha J, Hadar R, B. Horwitz A. tmkA, a MAP kinase of Trichoderma virens, is involved in biocontrol properties and repression of conidiation in the dark. Eukaryot Cell 2003; 2: 446-55.

[36] Neer EJ. Heterotrimeric G proteins: organizers of transmembrane signals. Cell 1995; 80(2): 249-57.

[37] Lafon A, Han KH, Seo JA, Yu JH, d'Enfert C. G-protein and cAMP-mediated signaling in Aspergilli: a genomic perspective. Fungal Genet Biol 2006; 43(7): 490-502.

[38] Bolker M. Sex and crime: heterotrimeric G proteins in fungal mating and pathogenesis. Fungal Genet Biol 1998; 25(3): 143-56.

[39] Reithner B, Brunner K, Schuhmacher R, et al. The G protein alpha subunit Tgal of Trichoderma atroviride is involved in chitinase formation and differential production of antifungal metabolites. Fungal Genet Biol 2005; 42: 749-60.

[40] Brunner K, Omann M, Pucher ME, et al. Trichoderma G proteincoupled receptors: functional characterisation of a cAMP receptorlike protein from Trichoderma atroviride. Curr Genet 2008; 54(6): 283-99.

[41] Shoresh M, Harman GE, Mastouri F. Induced systemic resistance and plant responses to fungal biocontrol agents. Annu Rev Phytopathol 2010; 48: 21-43.

[42] Shoresh M, Gal-On A, Leibman D, Chet I. Characterization of a mitogen-activated protein kinase gene from cucumber required for Trichoderma-conferred plant resistance. Plant Physiol 2006; 142: 1169-79.

[43] Zeilinger S. In: Arora, D.K. Ed. Handbook of Fungal Biotechnology. Marcel Dekker, Inc: New York 2004; pp. 181-92.
[44] Di Pietro A, Garcia-MacEira FI, Meglecz E, Roncero MI. A MAP kinase of the vascular wilt fungus Fusarium oxysporum is essential for root penetration and pathogenesis. Mol Microbiol 2001; 39: 1140-52.

[45] Barbara R, Rainer S, Norbert S, Marion P, Kurt B, Zeilinger S. Signaling via the Trichoderma atroviride mitogen-activated protein kinase Tmk1 differentially affects mycoparasitism and plant protection. Fungal Genet Biol 2007; 44: 1123-33.

[46] Olmedo-Monfil V, Mendoza-Mendoza A, Go'mez I, Corte's C, Herrera- Estrella A. Multiple environmental signals determine the transcriptional activation of the mycoparasitism related gene prb1 in Trichoderma atroviride. Mol Genet Genomics 2002; 267: 70312.

[47] Mendoza MA, Pozo MJ, Grzegorski D, et al. Enhanced biocontrol activity of Trichoderma through inactivation of a mitogen-activated protein kinase. Proc Natl Acad Sci USA 2003; 100(26): 15965-70.

[48] $\mathrm{Xu}$ JR, Hamer JE. MAP kinase and cAMP signaling regulate infection structure formation and pathogenic growth in the rice blast fungus Magnaporthe grisea. Genes Dev 1996; 10: 2696-706.

[49] Kultz D. Phylogenetic and functional classification of mitogen- and stress-activated protein kinases. J Mol Evol 1998; 46: 571-88.

[50] Mendoza-Mendoza A, Pozo MJ, Grzegorski D, et al. Enhanced biocontrol activity of Trichoderma through inactivation of a mitogen-activated protein kinase. Proc Nat Acad Sci USA 2003; 100: $15965-70$.

[51] Serrano-Carreon L, Flores C, Rodriguez B, Galindo E. Rhizoctonia solani, an elicitor of 6-pentyl-alpha-pyrone production by Trichoderma harzianum in a two liquid phases, extractive fermentation system. Biotechnol Lett 2004; 26: 1403-6.

[52] Dixon K, Xu JR, Smirnoff N, Talbot NJ. Independent signaling pathways regulate cellular turgor during hyperosmotic stress and appressorium-mediated plant infection by Magnaporte grisea. Plant Cell 1999; 11: 2045-58.

[53] Kronstad J, De Maria AD, Funnell D, et al. Signaling via cAMP in fungi: interconnections with mitogen-activated protein kinase pathways. Arch Microbiol 1998; 170(6): 395-404.

[54] Dickman MB, Yarden O. Serine/threonine protein kinases and phosphatases in filamentious fungi. Fungal Genet Biol 1999; 26(2): 99-117.

[55] Seidl V, Schmoll M, Scherm B, et al. Antagonism of Pythium blight of zucchini by Hypocrea jecorina does not require cellulase gene expression but is improved by carbon catabolite derepression. FEMS Microbiol Lett 2006; 257(1): 145-51.

[56] Silva RN, da Silva SP, Brandão RL, Ulhoa CJ. Regulation of Nacetyl-beta-D-glucosaminidase produced by Trichoderma harzianum: evidence that cAMP controls its expression. Res Microbiol 2004; 155: 667-71.

[57] Casas FS, Rios MM, Rosales TS, Martínez PH, Olmedo VM, Herrera AE. Cross talk between a fungal blue-light perception system and the cyclic AMP signaling pathway. Eukaryot Cell 2006; 5(3): 499-506.

[58] Gresik M, Kolarova N, Farkas V. Membrane potential, ATP and cyclic AMP changes induced by light in Trichoderma viride. Exp Mycol 1988; 12: 295-301.

[59] Nemcovic M, Farkas V. Stimulation of conidiation by derivates of cAMP in Trichoderma viride. Folia Microbiologica 1998; 43(4): 399-402.

[60] Mukherjee M, Mukherjee PK, Kale SP. cAMP signalling is involved in growth, germination, mycoparasitism and secondary metabolism in Trichoderma virens. Microbiology 2007; 153: 1734-42.

[61] Vázquez MM, César S, Azcón R, Barea JM. Interactions between arbuscular mycorrhizal fungi and other microbial inoculants (Azospirillum, Pseudomonas, Trichoderma) and their effects on microbial population and enzyme activities in the rhizosphere of maize plants. Appl Soil Ecol 2000; 15: 261-72.

[62] Al-Asbahi AAS. Arbuscular mycorrhizal protein mRNA overexpression in bread wheat seedlings by Trichoderma harzianum Raifi (KRL-AG2) elicitation. Gene 2012; 494: 209-13.

[63] Haneefat OE, Sobowale AA, Ilusanya OAF, Feyisola RT. The influence of Glomus mosseae and Trichoderma harzianum on phytohormone production in soybeans (Glycine max L. Merr) planted in sterilized and unsterilized soils. Am J Exp Agric 2012; 2(3): 516-24. 
[64] Martinez A, Obertello M, Pardo A, Ocampo JA, Godeas A. Interactions between Trichoderma pseudokoningii strains and the arbuscular mycorrhizal fungi Glomus mosseae and Gigaspora rosea. Mycorrhiza 2004; 14: 79-84.
[65] Medina AM, Pascual JA, Lloret E, Rold'an A. Interactions between arbuscular mycorrhizal fungi and Trichoderma harzianum and their effects on Fusarium wilt in melon plants grown in seedling nurseries. J Sci Food Agric 2009; 89: 1843-50.

Received: November 21, 2013

Revised: January 07, 2014

Accepted: March 31, 2014

(c) Sarma et al.; Licensee Bentham Open.

This is an open access article licensed under the terms of the Creative Commons Attribution Non-Commercial License (http://creativecommons.org/ licenses/by-nc/3.0/), which permits unrestricted, non-commercial use, distribution and reproduction in any medium, provided the work is properly cited. 